\title{
Armadilhas da abertura financeira
}

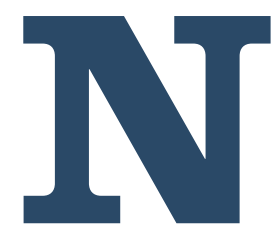

osúltimos 20 anos, a onda de desregulamentação tem atingido os mercados centrais. As palavras de ordem passaram a ser abertura comercial, liberalização das contas de capital, descompressão dos sistemas financeiros domésticos, reforma do Estado, abandono das políticas intervencionistas e câmbio flutuante. Todos os países, incluindo o Brasil, foram afetados por essas novas obrigações econômicas. Este artigo analisa o impacto da liberal ização do mercado sobre o crescimento econômico brasileiro.

por Luiz Gonzaga Belluzzo Unicamp

Em um sistema internacional "regulado", como o desenhado em 1944, em Bretton Woods, as regras do jogo eram as seguintes: taxas fixas, mas ajustáveis, de câmbio; limitada mobilidade de capitais; e cobertura de déficits em transações correntes (problemas de liquidez) atendida por uma instituição pública multilateral.
Câmbio ejuros, nesse sistema, eram preços-âncora, cujas relativas estabilidade e previsibilidadeeram vistas como essenciais para a formação das expectativas dos possuidores de riqueza envolvidos nas decisões de produção e investimento.

Em sua concepção original, o Fundo Monetário Internacional deveria funcionar, portanto, como um provedor de 
liquidez aos países com desequilíbrio de curto prazo no balanço de pagamentos. 0 artigo VII de seus estatutos - a chamada cláusula da "moeda escassa" - previa, sim, a adoção de controles cambiais em situações de agudo desequilíbrio do balanço de pagamentos.

Esse modo de regulação tinha como objetivo impedir que condicionantes ou choques externos passassem a comandar a política econômica doméstica e a definir a trajetória das economias nacionais. Os controles cambiais - sobretudo na conta de capital - eram prática corrente: as políticas monetárias e fiscais e os sistemas financeiros nacionais deveriam estar voltados para a sustentação de taxas elevadas de crescimento econômico e para a maximização do bem-estar dos cidadãos. "especulativas" nos mercados de riqueza (ações e imóveis), com conseqüências indesejáveis para a solidez dos sistemas bancários. A queda das barreiras que separavam os bancos comerciais dos bancos de investimento e de negócios suscitou, como era previsível, a formação de bol has nos mercados de ativos, elevando o risco de crises sistêmicas.

Em um movimento sincronizado, o FMI eo Banco Mundial - em nome das chamadas políticas estruturais - dedicaram-se a pressionar os países da periferia com o propósito de obrigá-los, entre outras coisas, a eliminar os controles ou obstáculos à livre entrada e saída de capitais.

As pal avras de ordem do "novo consenso" eram: abertura comercial; liberalização das contas de capital; desregulamentação e "descompressão" dos sistemas financeiros domésticos; e reforma do Estado, incluindo a privatização de empresas públicas e da seguridade social, e o abandono das políticas "intervencionistas" de fomento às exportações, à industria e à agricultura.

Um após outro, os países demoeda não-conversível promoveram a abertura financeira. Os ciclos de financiamento externo do final do sé culo XX einício do XXI foram curtos e de reversão muito rápida. As economias periféricas ficaram, assim, expostas às ondas de otimismo e pessimismo inerentes aos mercados "globalizados".

20 anos, a desregulamentação dos mercados e a crescente liberalização dos movimentos de capitais entre as principais praças de negócios assumiram uma velocidade espantosa. N os países centrais, ao contrário da "globalização financeira" do último quartel do século XIX - que instituiu o padrãoouro e seu sistema de taxas fixas -, os regimes cambiais caminharam na direção de um sistema detaxas flutuantes. Tratava-se de escapar das aporias da "trindade impossível", ou seja, da convivência entre taxas fixas, mobilidade de capitais e autonomia da política monetária doméstica.

A desregulamentação financeira, ao mesmo tempo, rompeu os diques de segurança erigidos depois da crise dos anos 1930. Essas restrições buscavam impedir que os bancos comerciais se envolvessem no financiamento de posições
Reflexos latinos. Na América Latina, as políticas de liberalização financeira e de ancoragem cambial, além de agravarem as condições de vida dos mais pobres, afetaram negativamente o crescimento econômico. No Brasil e, sobretudo, na Argentina, a abertura financeira inflou os passivos externos e a dívida pública e facilitou as aquisições de empresas locais em todos os setores. 0 resultado foi a fragilização do bal anço de pagamentos, a crescente imobilização da política fiscal e a subordinação da política monetária à alternância de otimismo e pessimismo nos mercados globais.

Alguns países tentaram escapar da coerção cambial como o Brasil - adotando o câmbio flutuante. A âncora no- 
minal, nesse caso, fica por conta do regime de metas de inflação. A experiência recente demonstra, no entanto, que a dependência excessiva do financiamento externo engendra miniciclos de euforia, seguidos de forte instabilidade cambial.

O Banco Central não recuperou, assim, a liberdade para guiar a taxa de juros de modo a permitir que a economia nacional pudesse evoluir em um ambiente favorável à expansão do crédito, ao investimento, ao endividamento das famílias e das empresas.

Nos dias de hoje, a abertura e a descompressão financeiras nos países da periferia inverteram as determinações do balanço de pagamentos. São os movimentos especulativos e de arbitragem das massas de capital monetário que, afetando a taxa de câmbio nominal, determinam os resultados em conta corrente. No imediato pós-guerra, período da repressão financeira, a conta de capital era um resíduo que "fechava" os déficits na conta de mercadorias e serviços.

No admirável mundo novo, de ajustamentos rápidos eal ta volatilidade de preços dos ativos, países dotados de moedas frágeis, com desprezível participação nas transações internacionais, encontram-se diante do risco de uma procissão de desgraças: valorização indesejada da moeda local,

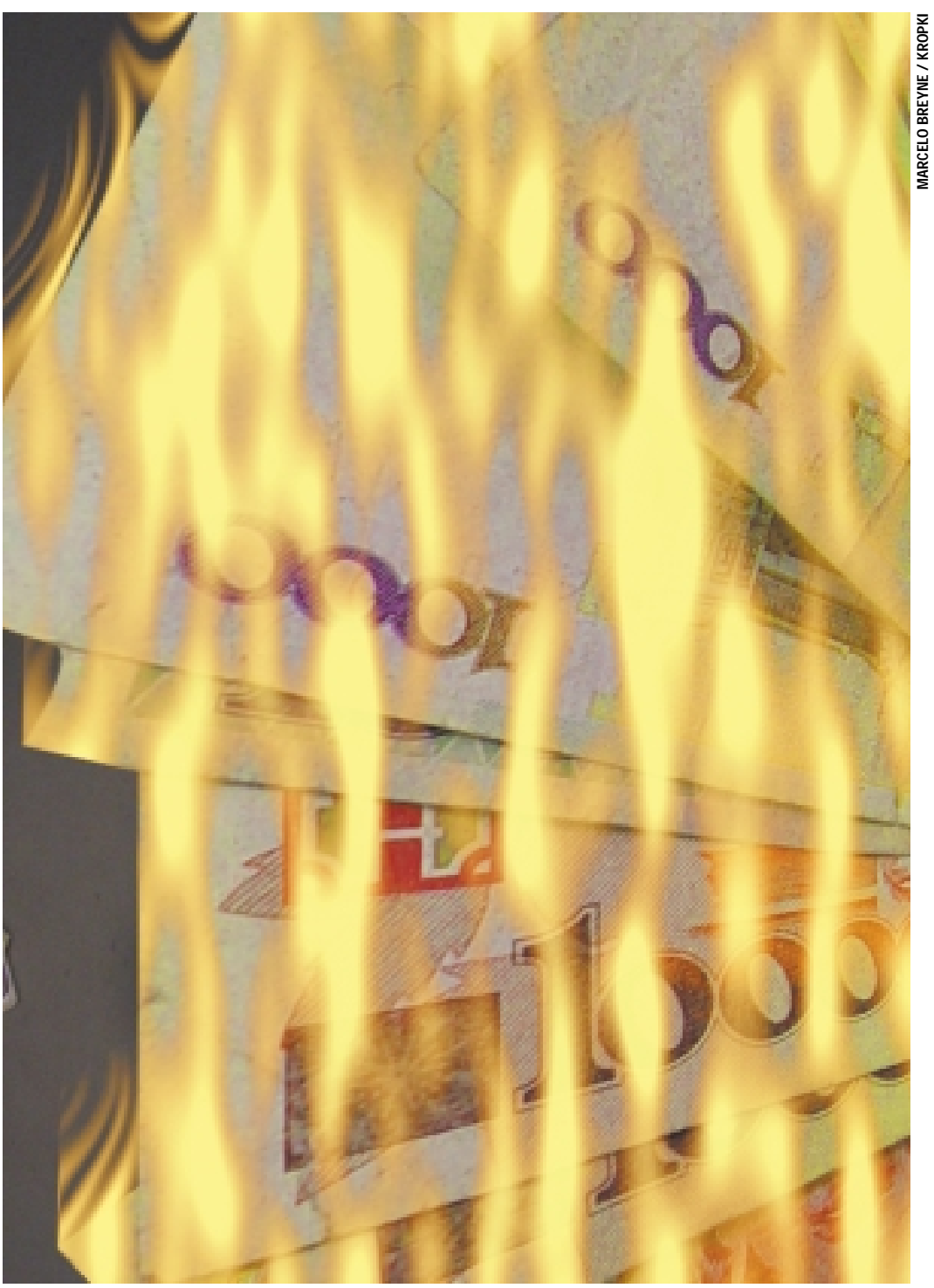
operações de esterilização dos efeitos monetários da expansão das reservas (explosão da dívida pública), déficits insustentáveis em conta corrente e, finalmente, crises cambiais e financeiras.

A situação brasileira. No Brasil, as aberturas comercial e financeira desenharam um quadro macroeconômico cuja marca registrada foi a constituição de um elevado passivo externo líquido, hoje calculado em US\$ 400 bilhões. Na segunda metade da década de 1990, entre 1995 e2000, o país acumulou um déficit em conta corrente (balança comercial e balança de serviços) de mais deUS\$ 150 bilhões, financiado

pelo endividamento externo privado e pela venda de ativos públicos e particulares.

A desvalorização do real em 1999 e a adoção de um regime de câmbio flutuante contribuíram para a el evação do saldo comercial e para a redução do déficit em conta corrente - um movimento lento entre 1999 e2001 emais rápido a partir de 2002. Porém, mantida a abertura na conta de capitais, o país continuou sujeito à volatilidade da taxa de câmbio, acompanhada deelevadas taxas de juros reais. Essa combinação infausta vem determinando uma trajetória de stop and go, em que o (baixo) crescimento é periodicamente interrompido. 
Em um mundo de intensa mobilidade de capitais, a entrada de recursos externos permite um miniciclo de consumo e uma tendência à sobreval orização cambial. Já a ameaça de fuga provoca, automaticamente, uma pressão sobre a moeda local e a subida da taxa de juros. A instabilidade dessas variáveis macroeconômicas - permanentemente submetidas às tensões que derivam das avaliações dos agentes nos mercados financeiros e de capitais - não permite a execução de políticas de crescimento.

Na década de 1990, além da valorização cambial, as reformas liberais promoveram choques negativos na economia. Primeiro, a elevação dos custos gerais do sistema produtivo, resultado da privatização das empresas públicas que ofertavam insumos gerais a baixo custo, como energia, telecomunicações e transporte; segundo, foi desmantelada a articulação que sempre existiu no Brasil entre investimento público e investimento privado; terceiro, a "reestruturação produtiva" e a desnacionalização tornaram as importações mais "sensíveis" ao crescimento do PIB. Essa elasticidade das importações deve ser ainda maior quando o investimento aumentar. estável para as decisões de produção, de investimento e de exportação, além de comprometerem as metas de inflação. É fácil compreender que, diante da incerteza quanto ao rumo dos "preços-chave" da economia - juros, câmbio esalários-, 0 horizonte temporal das decisões de investimento encurtase dramaticamente.

$\mathrm{Na}$ atual conjuntura de restrição externa, a elevação da taxa de crescimento da economia brasileira - acompanhada do aumento virtuoso do investimento e do saldo comercial deveria supor, como primeira condição, uma taxa de expansão da demanda externa maior do que o ritmo em que avança a demanda doméstica.

A balança comercial vem apresentando bons resultados: é provável que o superávit na conta de mercadorias chegue aos US 16 bilhões em 2003. Uma boa notícia, mas não um resultado saudável: a despeito da recuperação dos preços das commodities e do crescimento das exportações nos últimos meses, a baixa atividade doméstica vem contribuindo para 0 fraco desempenho das importações.

0 país marcou passo no que se refere à sua pauta de exportações, concentrando as receitas nos produtos cujas vendas crescem menos quando a demanda externa aumenta (commodities agrícolas e industriais) e tornando as exportações mais dependentes de mercados e países (América Latina) que estão encalacrados na recessão e em problemas graves de financiamento do balanço de pagamentos. N essas condições, o câmbio real ganha maior relevo: quanto mais fraco, melhor - o que dificulta o bom desempe-

Imagino que o presidente Lula ficaria satisfeito com um crescimento de $4 \%$ do PIB nos três últimos anos de seu mandato. Certamente espera um superávit comercial ainda maior do que os US\$13,5 bilhões do ano passado. Sendo assim, é bom não esquecer: é muito difícil - mesmo com câmbio flutuante - combinar bons resultados na balança de transações correntes etaxas de crescimento mais elevadas sem uma subida expressiva do investimento público e privado.

O crescimento econômico brasileiro. A economia brasileira terá de se libertar dos humores da finança global. As oscilações de câmbio impedem a formação de um ambiente nho da política de metas de inflação.

Tais contradições entre a política cambial e a monetária desenvolvem-se em um quadro estrutural adverso: a dilaceração de al gumas cadeias produtivas ea estagnação dos investimentos nas últimas duas décadas. Esses "gargal os" na estrutura da oferta só serão reparados com o aumento imediato dos gastos na formação de nova capacidade, o que vai reclamar políticas adequadas de crédito e outros estímulos. Sem essa providência, as taxas de crescimento almejadas vão "consumir" rapidamente a capacidade na siderurgia, na petroquímica e no setor de não-ferrosos, além de exacerbar os "buracos" nos setores de tecnologia avançada. Isso para 
não falar dos investimentos em infraestrutura.
Na atual conjuntura de restrição externa, a elevação da taxa de crescimento da economia

Medidas para o brasileira deveria supor, como primeira condição, crescimento econômico. Dada a desigualdade distributiva vigente no país, 0 desejo de combinar crescimento mais el evado e aumento do saldo comercial só pode ser satisfeito se houver: 1) uma política muito agressiva de exportações; 2) políticas de gasto e financiamento destinadas a desobstruir os gargal os na infra-estrutura e nos insumos; e 3) uma política tributária e fiscal capaz de moderar a expansão do consumo das camadas de alta renda, na mesma proporção em que permite o crescimento da renda dos mais pobres.

A combinação entre crescimento dos investimentos e aumento do saldo comercial vai impor um maior "vazamento" da renda criada para os reservatórios de pou-

pança - voluntária ou fiscal. Não se trata aqui de anuir à tese da poupança macroeconômica como condição prévia para o investimento. No caso em exame, a exigência de um aumento na "taxa de poupança" tem a ver com a necessidade de se economizar moeda forte e formar reservas al entadas.

Luiz Gonzaga Belluzzo

Prof. Titular do Instituto de Economia da UNICAMP

Doutor em Economia pela UNICAMP

E-mail: belluzzo@aol.com

\section{Os descaminhos do mercado global}

0 Nobel de Economia em 2001, Joseph E. Stiglitz, tem um nítido posicionamento crítico dos rumos da econômica mundial. Abaixo destacamos algumas passagens de seu pensamento sobre globalização, fluxo de capitais e crescimento econômico.

"Os críticos da globalização, que acusam os países ocidentais de hipocrisia, estão certos. Os países do Ocidente forçaram as nações pobres a eliminar as barreiras comerciais, mas eles próprios mantiveram as suas, impedindo que os países em desenvolvimento exportassem seus produtos agrícolas, privando-os, assim, da renda tão desesperadamente necessária obtido por meio das exportações."

"O fluxo de dinheiro volátil para dentro e para fora do país, que muitas vezes ocorre depois da liberalização do mercado de capitais, deixa um rastro de devastação. Os pequenos países em desenvolvimento são como pequenos barcos. Uma liberalização rápida do mercado de capitais, da maneira imposta pelo FMI, equivale a fazer com eles façam uma viagem em mares revoltos antes que os furos em seus cascos tenham sido consertados, antes que 0 capitão tenha recebido treinamento, antes que os coletes salva-vidas tenham sido colocados a bordo. Mesmo na melhor das circunstâncias, há uma grande probabilidade de esses barcos afundarem quando forem atingidos no costado por uma grande onda."

"O que torna as especulação lucrativa é o dinheiro proveniente dos governos, apoiados pelo FMI. Quando o Fundo e o governo brasileiro, por exemplo, gastaram aproximadamente 50 bilhões de dólares para manter sua taxa cambial em um nível supervalorizado no fim de 1998, para onde foi o dinheiro? Ele não desaparece no ar, acaba indo para o bolso de alguém grande parte desse dinheiro foi para o bolso de especuladores. Alguns destes podem ganhar, alguns podem perder, mas os especuladores como um todo somam uma quantidade igual à que 0 governo perde. De certa forma, é o FMI que mantém os especuladores em atividade."

Trechos extraídos do livro A globalização e seus malefícios, de Joseph E. Stiglitz. São Paulo: Editora Futura, 2002. 